\title{
Virtual care can't fix physician shortages underlying access woes
}

— Cite as: CMAJ 2019 September 3;191:E975-6. doi: 10.1503/cmaj.1095813

Posted on cmajnews.com on August 15, 2019.

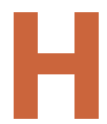

ealth systems are increasingly looking to telemedicine to bridge gaps in access to care. But tools like video chat won't help if there aren't enough health workers to answer when patients call, warned physicians at the 2019 Canadian Medical Association Health Summit.

Canada's wait times crisis is a health human resources crisis, according to Ontario Medical Association President Dr. Sohail Gandhi. Report after report show that Canadians pay more for worse access to care than their peers in other rich countries with universal health care, he said. "One of the things that never seems to get linked to these reports is the low number of physicians we have on a per capita basis."

While Canada has 2.8 physicians per 1000 people, countries that outrank Canada in health care comparisons have more than 3 per 1000 people. Top performers like Sweden, Denmark, Norway, Switzerland and Germany have more than 4 physicians per 1000 people. Whatever strategies Canada takes to improve

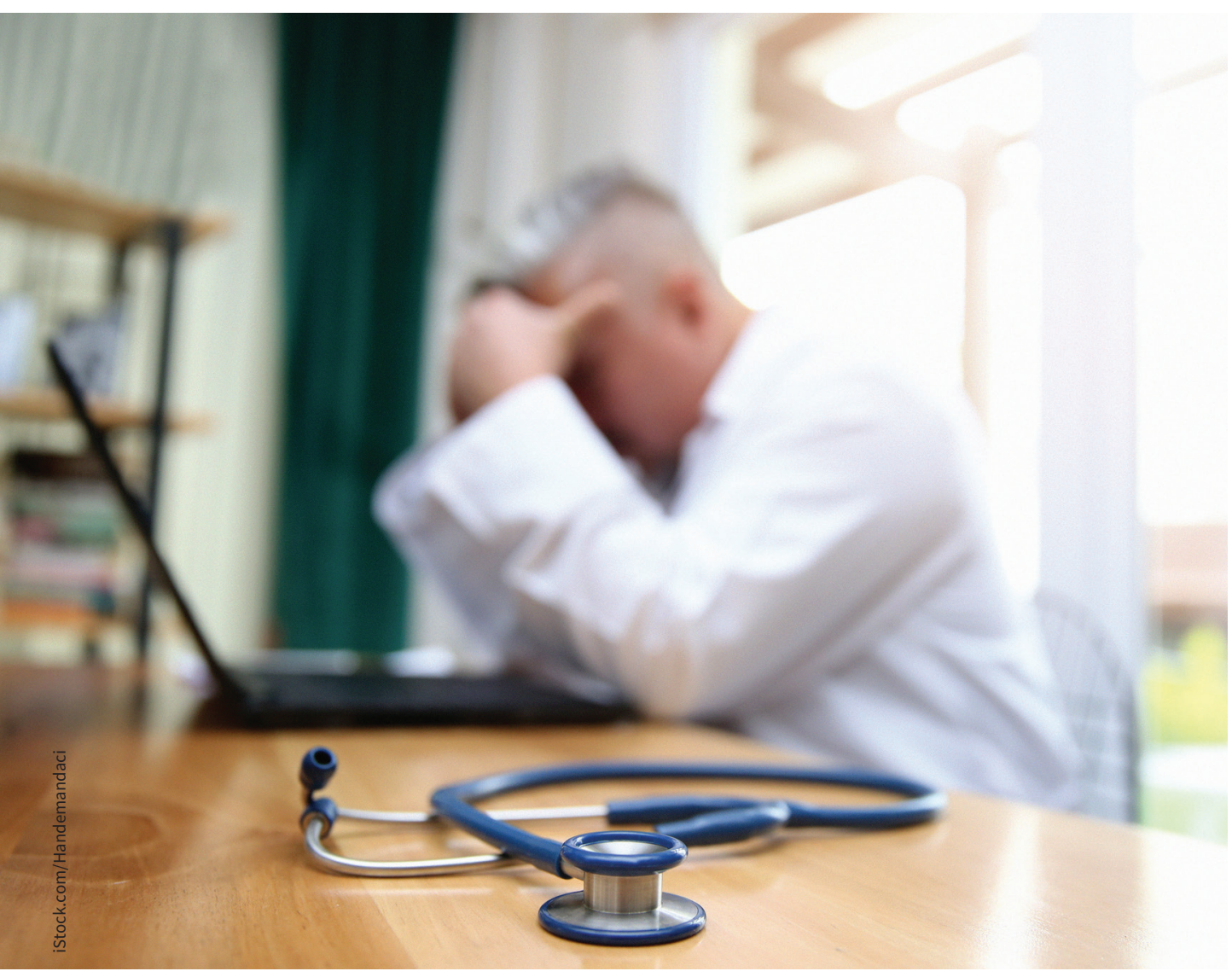

Without more health workers, strategies to improve access won't work, said the president of the Ontario Medical Association at a recent health summit. access, "without more people... they're not going to work," Gandhi said.

According to health systems expert Dr. Charles Alessi, "there's a global shortage of health workers and it's becoming more acute." Alessi realized the extent of the problem when, travelling around the world, he kept seeing the same people working in different health systems. "Countries were beating each other in terms of who pays more, and the workforce was basically moving around the world," he explained. Compared with growing demand for health services from aging and increasingly complex patient populations, the global health workforce is "quite small and getting smaller."

Burnout and decreasing satisfaction in health professions are compounding the problem, Alessi added. The drive for "value" in health care requires more nuanced conversations and shared decisions with patients. But time, training and trust to do that are often lacking, he said. "It puts a strain on anybody."

Patients, health providers and payers may also have very different definitions of "value," Alessi noted. Governments, for example, are keen on virtual care to make health services more efficient and close geographic distance between patients and providers. However, doctors and patient advocates at the summit stressed that virtual care should augment, not replace face-toface connection. 
The First Nations Health Authority in British Columbia shifted the focus of its telemedicine expansion project from laying cables to strengthening relationships after receiving similar feedback from Indigenous patients. "Communities were clear with us that they wanted a two-way conversation," said Chief Medical Officer Dr. Evan Adams. Access to care, despite stark disparities in many communities, wasn't their top concern. Many patients were more concerned about how virtual care would affect communication between their different health providers. "They asked that we speak to each other more and often complain that we seem not to know each other."

Indigenous patients also raised concerns about cultural safety and humility in virtual care. "Most of our clients don't complain a lot, and when they do, it's about professional conduct, about having a disrespectful experience, and not about a lack of care or medical mismanagement," Adams said. Addressing these concerns led to better access to timely urgent care and clinical expertise in the management of chronic diseases, he added. "The patient is looking for a kinder service, not one that's more efficient."

Lauren Vogel, CMAJ 